\title{
Structural equation modeling of the proximal- distal continuum of adherence drivers
}

\author{
This article was published in the following Dove Press journal: \\ Patient Preference and Adherence \\ 7 November 2012 \\ Number of times this article has been viewed
}

\author{
Colleen A McHorney' \\ Ning Jackie Zhang ${ }^{2}$ \\ Timothy Stump ${ }^{3}$ \\ Xiaoquan Zhao ${ }^{4}$ \\ 'US Outcomes Research, Merck, \\ North Wales, PA, ${ }^{2}$ University of \\ Central Florida, Orlando, ${ }^{3}$ Indiana \\ University School of Medicine, \\ Indianapolis, ${ }^{4}$ George Mason \\ University, Fairfax, USA
}

Correspondence: Colleen A McHorney US Outcomes Research, Merck 35I N Sumneytown Pike, UG2MW-05, North Wales PA 19454, USA

Tel +l 2673052425

Fax + I 2673050860

Email colleen_mchorney@merck.com
Objectives: Nonadherence to prescription medications has been shown to be significantly influenced by three key medication-specific beliefs: patients' perceived need for the prescribed medication, their concerns about the prescribed medication, and perceived medication affordability. Structural equation modeling was used to test the predictors of these three proximal determinants of medication adherence using the proximal-distal continuum of adherence drivers as the organizing conceptual framework.

Methods: In Spring 2008, survey participants were selected from the Harris Interactive Chronic Illness Panel, an internet-based panel of hundreds of thousands of adults with chronic disease. Respondents were eligible for the survey if they were aged 40 years and older, resided in the US, and reported having at least one of six chronic diseases: asthma, diabetes, hyperlipidemia, hypertension, osteoporosis, or other cardiovascular disease. A final sample size of 1072 was achieved. The proximal medication beliefs were measured by three multi-item scales: perceived need for medications, perceived medication concerns, and perceived medication affordability. The intermediate sociomedical beliefs and skills included four multi-item scales: perceived disease severity, knowledge about the prescribed medication, perceived immunity to side effects, and perceived value of nutraceuticals. Generic health beliefs and skills consisted of patient engagement in their care, health information-seeking tendencies, internal health locus of control, a single-item measure of self-rated health, and general mental health. Structural equation modeling was used to model proximal-distal continuum of adherence drivers. Results: The average age was 58 years (range $=40-90$ years), and 65\% were female and 89\% were white. Forty-one percent had at least a four-year college education, and just under half $(45 \%)$ had an annual income of \$50,000 or more. Hypertension and hyperlipidemia were each reported by about a quarter of respondents ( $24 \%$ and $23 \%$, respectively). A smaller percentage of respondents had osteoporosis (17\%), diabetes (15\%), asthma $(13 \%)$, or other cardiovascular disease $(8 \%)$. Three independent variables were significantly associated with the three proximal adherence drivers: perceived disease severity, knowledge about the medication, and perceived value of nutraceuticals. Both perceived immunity to side effects and patient engagement was significantly associated with perceived need for medications and perceived medication concerns.

Conclusion: Testing the proximal-distal continuum of adherence drivers shed light on specific areas where adherence dialogue and enhancement should focus. Our results can help to inform the design of future adherence interventions as well as the content of patient education materials and adherence reminder letters. For long-term medication adherence, patients need to autonomously and intrinsically commit to therapy and that, in turn, is more likely to occur if they are both informed (disease and medication knowledge and rationale, disease severity, consequences of nonadherence, and side effects) and motivated (engaged in their care, perceive a need for medication, and believe the benefits outweigh the risks).

Keywords: compliance, prescription medications, medication beliefs, treatment beliefs 


\section{Introduction}

Over the past 40 years, numerous conceptual models have been proposed to explain medication nonadherence. ${ }^{1} \mathrm{~A}$ short listing of models that have been tested in relation to medication adherence include the Health Belief Model, ${ }^{2}$ the Theory of Reasoned Action, ${ }^{3}$ the Theory of Planned Behavior, ${ }^{4}$ the Transtheoretical Model, ${ }^{5}$ the Necessity-Concerns Framework, ${ }^{6}$ the Information-Motivation-Behavioral Skills model, ${ }^{7}$ and the Information-Motivation-Strategy model. ${ }^{8}$ Most of these frameworks belong to the family of models subsumed under social-cognitive theory, ${ }^{1}$ and these models have incrementally built on the conceptual and empirical learning of one another. At the heart of all of these frameworks, as well as others, are two guiding assumptions: (1) individuals make decisions about prescription medications (ie, patients do not passively and reflexively obey physician recommendations about prescription medications); and (2) medication adherence is influenced by an array of patient beliefs, attitudes, skills, and experiences.

In 2009, the Proximal-Distal Continuum of Adherence Drivers model was proposed. ${ }^{9}$ In the proximal-distal continuum, it was asserted that some adherence determinants are nearer or closer to patients' medication-taking decisions (proximal) while others are more removed (further from) patients' adherence decisions. The aim of the proximaldistal continuum was to organize the numerous hypothesized medication adherence drivers along an etiological continuum of determinants ranging from those shown to have strong empirical relationships with adherence (proximal drivers) to those with weaker relationships (distal drivers). In short, the proximal-distal continuum consists of an etiological hierarchy of hypothesized adherence drivers in order to account for medication adherence in a multifactorial manner.

The proximal-distal continuum is based upon three fundamental tenets. First, an adherent "personality" does not exist - the same individual can be adherent to one medication, not fill a second medication prescription, decide to stop taking a third medicine without the advice of their provider, and be careless taking a fourth medication. ${ }^{9}$ A growing body of research has demonstrated that individual patients have different adherence patterns and levels for assorted medications, both within a therapeutic class ${ }^{10-12}$ as well as across therapeutic areas. ${ }^{13-16}$ Intraindividual variability in medication taking occurs because patients have different beliefs about different prescribed medications and their attendant diagnosed conditions. Second, patient beliefs, skills, and experiences that influence medication adherence can be either specific to a prescribed medication or disease or they can be generic in nature (ie, nonspecific to a prescribed medication or disease). In general, patient beliefs, skills, and experiences specific to a prescribed medication or disease tend to be more predictive of adherence than generic psychosocial beliefs and skills. ${ }^{9}{ }^{17-21}$ Third, for many patients, a new diagnosis and the attendant prescribed therapy represents uncertainty and is a threat to the status quo. ${ }^{22}$ The short-term benefits of prescription-medication therapy can seem intangible to patients, especially to those with asymptomatic chronic disease. The long-term benefits of prescription medications are probabilistic and can be so distant in the future that patients may heavily discount them. Viewed through the uncertainty lens, nonadherence can make sense from the patient perspective because taking prescription medications represents a risky prospect in the short term (short-term financial, psychological, and opportunity costs, and risk of side effects) with uncertain long-term benefits (probabilistic reductions in mortality, morbidity, and complications) compared to the status quo (health as it is)..$^{23}$

At the proximal end of the continuum are patients' beliefs about the prescribed medication (Figure 1). Research over the past 20 years has consistently demonstrated that patients' beliefs about a prescribed medication are potent predictors of medication adherence. Next, etiologically, are patients' sociomedical and disease-related beliefs, skills, and experiences which are hypothesized to be direct determinants of patients' proximal medication beliefs. Patients' generic beliefs, skills, and experiences are hypothesized to directly influence the disease-related and sociomedical beliefs. Finally, the most distal variables encompass demographic characteristics. Meta-analytic research has demonstrated weak associations between sociodemographic characteristics and adherence. ${ }^{24}$

A large body of research has provided evidence about the relative influence of the myriad adherence drivers potentially subsumed under the proximal-distal continuum. The vast majority of these studies have examined medication adherence as the outcome variable. However, few studies have modeled the determinants of proximal medication beliefs - beliefs demonstrated by past research to be powerful predictors of medication adherence. Nonadherence to prescription medications has been shown to be significantly influenced by three key medication-specific beliefs: patients' perceived need for the prescribed medication, ${ }^{9,18,19,25-37}$ their concerns about the prescribed medication, $, 18,19,26,29,30,33,34,38-47$ and perceived medication affordability. ${ }^{9,48-55}$ We used structural equation 


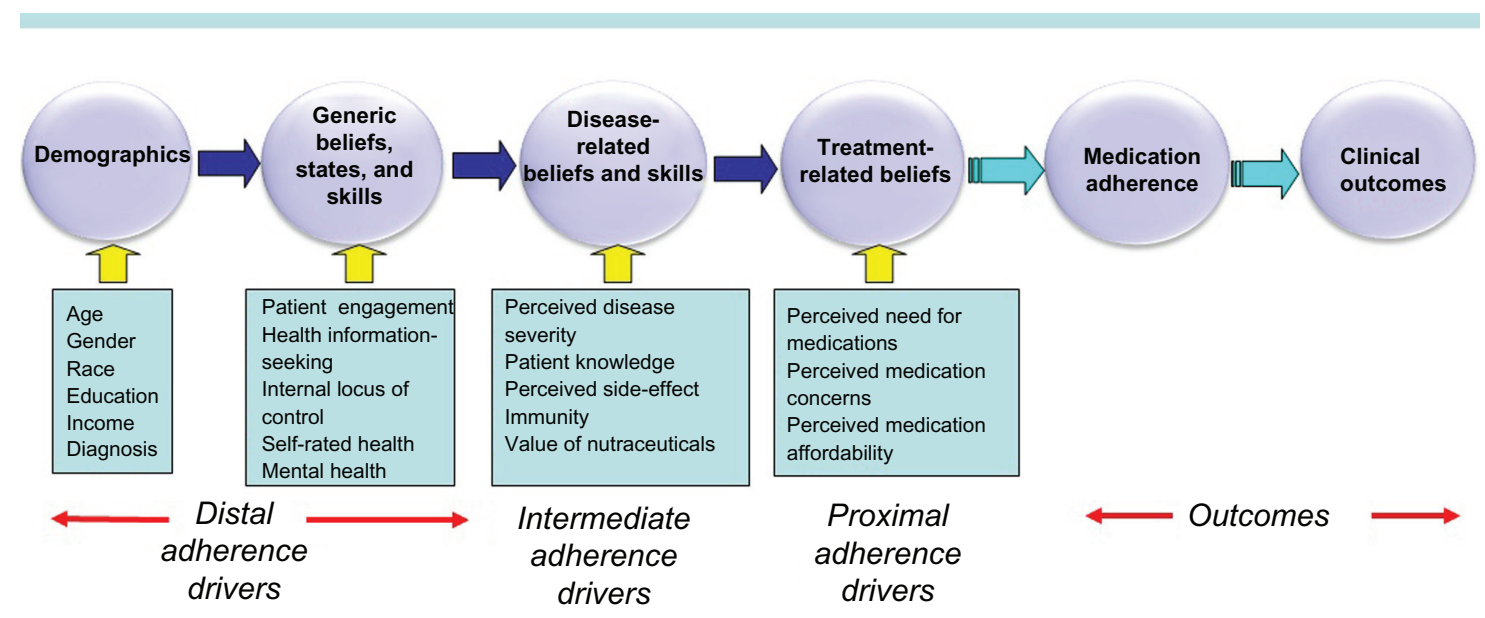

Figure I The proximal-distal continuum of adherence drivers.

modeling (SEM) to test the predictors of these three proximal determinants of medication adherence. The goal of testing the proximal-distal continuum was to shed light on the origins of the three key proximal medication beliefs. This information can contribute insights as to how future adherence interventions may be made more efficacious by identifying underlying mechanisms influencing perceived need for medications, perceived medication concerns, and perceived medication affordability.

\section{Methods \\ Study design}

\section{Sampling procedure}

As described in detail elsewhere, ${ }^{9}$ in Spring 2008, survey participants were selected from the Harris Interactive Chronic Illness Panel, an internet-based panel of hundreds of thousands of adults with chronic disease. Respondents were eligible for the survey if they were aged 40 years and older, resided in the US, and reported having at least one of six chronic diseases prevalent among US adults: asthma, diabetes, hyperlipidemia, hypertension, osteoporosis, or other cardiovascular disease (CVD) (eg, angina, myocardial infarction, congestive heart failure). The six chronic diseases reflect a mix of symptomatic and asymptomatic conditions. They are some of the most highly prevalent conditions in the US ${ }^{56}$ and are associated with a significant clinical and economic burden for the US health care system. ${ }^{57}$ If eligible respondents reported more than one of the six target conditions, one was randomly selected as the index (study) disease. Panel members responding to an e-mail invitation were instructed to read the informed consent form and click on yes if they agreed to participate. The protocol for the survey was approved by the Essex Internal Review Board. A 26.5\% survey contact rate (per standards recommended by the American Association for Public Opinion Research $)^{58}$ was achieved. A total of 1072 adults completed the survey.

\section{Survey content}

The proximal, intermediate, and distal variables were all collected during a single survey administration. The proximal medication beliefs were measured by three multi-item scales: perceived need for medications $(\mathrm{k}=12$, Cronbach's alpha $=0.96$, illustrative item: "I am convinced of the importance of my prescription medication."); ${ }^{9}$ perceived medication concerns $(\mathrm{k}=10$, Cronbach's alpha $=0.90$ items, illustrative item: "I worry that my prescription medication will do more harm than good to me."); ${ }^{9}$ and perceived medication affordability $(\mathrm{k}=7$, Cronbach's alpha $=0.97$, illustrative item "I feel financially burdened by my out-ofpocket expenses for my prescription medication."). ${ }^{9}$ The intermediate disease-related and sociomedical beliefs and skills included four multi-item scales: perceived disease severity $(\mathrm{k}=3$, Cronbach's alpha $=0.76$, illustrative item: "I think that my condition is severe."); knowledge about the index medication $(\mathrm{k}=9$, Cronbach's alpha $=0.92$, illustrative item: "I understand exactly what the medication prescribed for me will do for me."); perceived immunity to side effects $(\mathrm{k}=3$, Cronbach's alpha $=0.90$, illustrative item: "My chances of experiencing negative side effects from a prescription drug are high."); and perceived value of nutraceuticals (ie, vitamins, minerals, and supplements) ( $\mathrm{k}=7$, Cronbach's alpha $=0.92$, illustrative item: "For me personally, I believe that vitamin, mineral, and herbal supplements can achieve better health results than prescription drugs can."). Generic health beliefs and skills were measured by patient engagement in their care $(\mathrm{k}=14$, Cronbach's 
alpha $=0.97$, illustrative item "My doctor and I have a real partnership in my health care."); health information-seeking tendencies $(\mathrm{k}=5$, Cronbach's alpha $=0.91$, illustrative item: "I actively seek out information on my illnesses."); internal health locus of control using Wallston's measure $(\mathrm{k}=10$, Cronbach's alpha $=0.89) ;{ }^{59}$ general mental health using the Mental Health Inventory $(\mathrm{k}=5$, Cronbach's alpha $=0.88) ;{ }^{60}$ and a single-item measure of self-rated health (the "excellent-to-poor" item from the Medical Outcomes Study [MOS] Short-Form Health Survey [SF-36]). ${ }^{60}$ Evidence of the validity of these measures vis á vis the criterion of medication adherence has been previously published.9,61-64 With the exception of the Mental Health Inventory (a six-point scale ranging from "all of the time" to "none of the time"), health locus of control (a six-point scale ranging from "strongly disagree" to "strongly agree"), and the "excellent-to-poor" item (excellent, very good, good, fair, or poor), all items used a six-point categorical rating scale ranging from "agree completely" to "disagree completely." Each multi-item scale was computed using Likert's method ${ }^{65}$ of summated ratings in which each item is equally weighted and raw item scores are summed into a scale score. All scale scores were linearly transformed to a $0-100$ metric, with 100 representing the most favorable belief or state, 0 the least favorable, and scores in between representing the percentage of the total possible score.

Demographic variables were included in the model. Age was measured as a continuous variable. Gender and race were coded as $1=$ female vs $0=$ male and $1=$ white vs $0=$ nonwhite, respectively. Education was measured as a six-level interval variable with higher values indicating higher education. Income was measured with an 11-level interval variable with higher values indicating higher income. Each disease indicator was coded as $1=$ present vs $0=$ not present with hypertension selected as the reference group because it had the largest sample size of the six diseases.

\section{Statistical analysis}

Survey noncontact analysis

Logistic regression was used to assess differences between Chronic Illness Panel members with valid e-mail addresses who did and did not respond to the survey invitation (ie, survey noncontact bias per standards recommended by the American Association for Public Opinion Research). ${ }^{58}$ Independent variables for the logistic regression were age, gender, race, education, income, and geographic region of residence.

\section{Structural equation modeling (SEM)}

SEM was used in this analysis because some variables were both endogenous and exogenous, and traditional multivariate regression would not efficiently test the path relationships in one model. Twelve equations (three equations with the proximal beliefs as dependent variables, four equations with the intermediate beliefs and skills as dependent variables, and five equations with the generic beliefs, states, and skills as the dependent variables) were specified to represent the hypothesized relationships among the variables, which were treated as measured indicators of respondents' beliefs, states, and skills (see Figure 1). A single multivariate path model of these structural equations ${ }^{66-69}$ was estimated by modeling the covariance matrix among the observed variables. As shown in Figure 1, the three proximal beliefs were specified to be associated with the intermediate, disease-related beliefs and skills, which in turn were associated with the distal generic beliefs and skills, and in turn with demographic characteristics.

SEM model fitting was performed in two steps. The first step was the execution of a full model to include all variables specified in the proximal-distal continuum (Figure 1). The final model, presented in Tables 2-4, includes only statistically-significant variables. Statistical significance, goodness-of-fit indices, and modification indices were used to guide the final model.

All available data were used in the analysis and were used as input into Mplus ${ }^{\odot}$ software (version 6.1; Muthén and Muthén, Los Angeles, CA). ${ }^{70}$ Full information maximum likelihood with the Mplus MLR estimator was used to estimate path coefficients and standard errors robust to nonnormality. The chi-square test and three fit indices (comparative fit index [CFI], root mean square error of approximation [RMSEA], and the standardized root mean square residual [SRMR]) provided an assessment of model fit. Good model fit was identified with chi-square ratio $<3.0$, $\mathrm{CFI}>0.95$, RMSEA $<0.05$, and SRMR $<0.08 .{ }^{71}$ Correlated error terms were freely estimated within each domain (generic beliefs, intermediate beliefs, and proximal beliefs). Mplus uses model modification indices to determine what parameters should be added to the model to improve model fit. Modification indices are chi-square statistics with one degree of freedom for the fixed and constrained parameters in a structural equation model. They estimate the change in the improvement in the likelihood-ratio chi-square statistic for the model if the corresponding parameter is respecified as a free parameter. Modifications that improve model fit are regarded as potential changes that can be made to the 
SEM model. The hypothesized relationships were tested based on their statistical significances of path coefficients.

\section{Results \\ Survey noncontact}

A $26.5 \%$ contact rate was achieved. Compared to those who were invited but did not respond to the survey, those successfully contacted were more likely to be age 55 and older, white, and college educated. ${ }^{9}$

\section{Sample characteristics}

As shown in Table 1, the average age of respondents was 58 years (range $=40-90$ years), and $65 \%$ were female and

Table I Sociodemographic characteristics

\begin{tabular}{|c|c|c|}
\hline \multirow[t]{2}{*}{ Sociodemographic characteristic } & \multicolumn{2}{|c|}{$N=1072$} \\
\hline & $\overline{\mathbf{N}}$ & $\%$ \\
\hline Mean age $( \pm S D)$ & & $58.3(10.4)$ \\
\hline Median age ( $\pm \mathrm{IQR})$ & & $58.0(17.0)$ \\
\hline Age $65+$ & 325 & $30.3 \%$ \\
\hline Female & 695 & $64.8 \%$ \\
\hline White & 928 & $89.4 \%$ \\
\hline Black & 56 & $5.4 \%$ \\
\hline Hispanic & 30 & $2.9 \%$ \\
\hline Other race & 24 & $2.3 \%$ \\
\hline Less than high school & 12 & $1.1 \%$ \\
\hline High school graduate & 167 & $15.6 \%$ \\
\hline Some college but no degree & 450 & $42.0 \%$ \\
\hline Bachelor's degree & 177 & $16.5 \%$ \\
\hline Some graduate school but no degree & 88 & $8.2 \%$ \\
\hline Graduate or professional degree & 178 & $16.6 \%$ \\
\hline Income $<\$ 15,000$ & 62 & $6.8 \%$ \\
\hline Income $\$ 15,000-\$ 24,999$ & 130 & $14.2 \%$ \\
\hline Income $\$ 25,000-\$ 34,999$ & 149 & $16.3 \%$ \\
\hline Income $\$ 35,000-\$ 49,999$ & 160 & $17.5 \%$ \\
\hline Income $\$ 50,000-\$ 74,999$ & 177 & $19.4 \%$ \\
\hline Income $\$ 75,000-\$ 99,999$ & 117 & $12.8 \%$ \\
\hline Income $\$ 100,000-\$ 124,999$ & 49 & $5.4 \%$ \\
\hline Income $\$ 125,000-\$ 149,999$ & 27 & $2.9 \%$ \\
\hline Income $\$ 150,000-\$ 199,999$ & 22 & $2.4 \%$ \\
\hline Income $\$ 200,000-\$ 249,999$ & 10 & $1.1 \%$ \\
\hline Income $>\$ 250,000$ & 11 & $1.2 \%$ \\
\hline Asthma & 144 & $13.4 \%$ \\
\hline Diabetes & 157 & $14.7 \%$ \\
\hline Hyperlipidemia & 249 & $23.2 \%$ \\
\hline Hypertension & 257 & $24.0 \%$ \\
\hline Osteoporosis & 180 & $16.8 \%$ \\
\hline Other cardiovascular disease & 85 & $7.9 \%$ \\
\hline \multicolumn{3}{|l|}{ Self-rated health } \\
\hline Excellent & 20 & $1.9 \%$ \\
\hline Very good & 219 & $20.4 \%$ \\
\hline Good & 419 & $39.1 \%$ \\
\hline Fair & 309 & $28.8 \%$ \\
\hline Poor & 105 & $9.8 \%$ \\
\hline
\end{tabular}

Abbreviations: SD, standard deviation; IQR, interquartile range.
$89 \%$ were white. Forty-one percent had at least a four-year college education and just under half (45\%) had an annual income of $\$ 50,000$ or more. Hypertension and hyperlipidemia were each reported by about a quarter of respondents $(24 \%$ and $23 \%$, respectively). A smaller percentage of respondents had osteoporosis $(17 \%)$, diabetes $(15 \%)$, asthma $(13 \%)$, or other CVD (8\%). A majority of the samples rated their health as good $(39.1 \%)$ or fair $(28.8 \%)$.

\section{Results of SEM}

Table 2 presents the standardized path coefficients from the SEM model for the proximal treatment beliefs. Goodness of fit indices showed good model fit with CFI $=0.973$, RMSEA $=0.031$ and SRMR $=0.032$. The chi-square test was statistically significant (chi-square $=248, \mathrm{df}=121$, $P<0.0001$ ), reflecting a relatively good model $\mathrm{fit}^{72}$ given the sample size and deviations from multivariate normality. ${ }^{73-75}$ The model fit was much improved compared to the baseline full model $($ chi-square $=299, \mathrm{df}=24, \mathrm{RMSEA}=0.104$ ) and an alternative model without considering modifications (chi-square $=324, \mathrm{df}=109, \mathrm{RMSEA}=0.043$ ).

Greater perceived need for medications was related to greater perceived disease severity $(\beta=0.480)$, less value placed on nutraceuticals $(\beta=-0.249)$, more knowledge about the index medication $(\beta=0.244)$, greater patient engagement in their care $(\beta=0.137)$, more perceived immunity to side effects $(\beta=0.119)$, and less information seeking $(\beta=-0.090)$. In addition, age was positively related to perceived need for medications. Compared to patients with hypertension, those with dyslipidemia, osteoporosis, or other CVD perceived less need for the index medication. Over two-thirds $(68.3 \%)$ of the variation in perceived need for medications was explained by these eight significant predictors.

Fewer medication concerns were associated with more perceived immunity to side effects $(\beta=0.353)$, less value placed on nutraceuticals $(\beta=-0.318)$, more knowledge about the index medication $(\beta=0.164)$, greater patient engagement in their care $(\beta=0.125)$, less information seeking ( $\beta=-0.084)$, less perceived disease severity $(\beta=-0.078)$, and less of an internal locus of control $(\beta=-0.051)$. As age increased, medication concerns decreased. Compared to patients with hypertension, those with dyslipidemia or osteoporosis had more medication concerns. One-half $(50.9 \%)$ of the variation in perceived medication concerns was explained by these nine significant predictors.

Better medication affordability was related to less perceived disease severity $(\beta=-0.233)$, greater income 
Table 2 Standardized path loadings of path model in predicting proximal beliefs

\begin{tabular}{|c|c|c|c|c|c|c|}
\hline \multirow{3}{*}{$\begin{array}{l}\text { Independent } \\
\text { variables }\end{array}$} & \multicolumn{6}{|l|}{ Proximal beliefs } \\
\hline & \multicolumn{2}{|c|}{$\begin{array}{l}\text { Perceived need for } \\
\text { medications }\end{array}$} & \multicolumn{2}{|c|}{$\begin{array}{l}\text { Perceived medication } \\
\text { concerns }\end{array}$} & \multicolumn{2}{|c|}{$\begin{array}{l}\text { Perceived medication } \\
\text { affordability }\end{array}$} \\
\hline & Standardized $\beta$ & SE & Standardized $\beta$ & SE & Standardized $\beta$ & SE \\
\hline Perceived disease severity & $0.480^{\ddagger}$ & 0.021 & $-0.078^{ \pm}$ & 0.026 & $-0.233^{\ddagger}$ & 0.030 \\
\hline Patient knowledge & $0.244^{\ddagger}$ & 0.031 & $0.164^{\ddagger}$ & 0.032 & $0.082^{ \pm}$ & 0.029 \\
\hline Perceived side-effect immunity & $0.119 \ddagger$ & 0.023 & $0.353^{\ddagger}$ & 0.024 & NS & NS \\
\hline Perceived value of nutraceuticals & $-0.249 \ddagger$ & 0.025 & $-0.318^{\ddagger}$ & 0.030 & $-0.222^{\ddagger}$ & 0.029 \\
\hline Patient engagement & $0.137^{\ddagger}$ & 0.027 & $0.125^{\ddagger}$ & 0.032 & NS & NS \\
\hline Information seeking & $-0.090^{\ddagger}$ & 0.021 & $-0.084^{ \pm}$ & 0.027 & NS & NS \\
\hline Internal health locus of control & NS & NS & $-0.05 \mathrm{I} *$ & 0.021 & NS & NS \\
\hline Self-rated health & NS & NS & NS & NS & $0.136^{\ddagger}$ & 0.032 \\
\hline Mental health & NS & NS & NS & NS & $0.10 \mathrm{I}^{ \pm}$ & 0.031 \\
\hline Age & $0.065^{\ddagger}$ & 0.018 & $0.094^{\ddagger}$ & 0.023 & $0.166^{\ddagger}$ & 0.026 \\
\hline Female & NS & NS & NS & NS & $-0.072^{ \pm}$ & 0.026 \\
\hline White race & NS & NS & NS & NS & NS & NS \\
\hline Education & NS & NS & NS & NS & $0.057^{*}$ & 0.028 \\
\hline Income & NS & NS & NS & NS & $0.23 I^{\ddagger}$ & 0.031 \\
\hline Asthma & NS & NS & NS & NS & NS & NS \\
\hline Diabetes & NS & NS & NS & NS & NS & NS \\
\hline Lipid & $-0.059^{\ddagger}$ & 0.018 & $-0.053^{*}$ & 0.022 & NS & NS \\
\hline Osteoporosis & $-0.08 I^{\ddagger}$ & 0.020 & $-0.059^{ \pm}$ & 0.022 & NS & NS \\
\hline Other CVD & $-0.045^{ \pm}$ & 0.017 & NS & NS & NS & NS \\
\hline R-square of model & 0.683 & 0.016 & 0.509 & 0.023 & 0.340 & 0.023 \\
\hline
\end{tabular}

$(\beta=0.231)$, less value placed on nutraceuticals $(\beta=-0.222)$, older age $(\beta=0.166)$, better self-rated health $(\beta=0.136)$, better mental health $(\beta=0.101)$, and more knowledge about the index medication $(\beta=0.082)$. Females found medications to be less affordable, while education was positively related to perceived medication affordability. One-third (34.0\%) of the variation in perceived medication affordability was explained by these nine significant predictors.

The four intermediate beliefs were then modeled as dependent variables (Table 3). Greater perceived disease severity was related to worse self-rated health $(\beta=-0.262)$, greater patient engagement in their care $(\beta=0.254)$, greater information seeking $(\beta=0.122)$, and worse mental health ( $\beta=-0.112)$. As education increased, perceptions of disease severity decreased. Compared to patients with hypertension, those with asthma or osteoporosis perceived their diseases to be less severe, while those with other CVD and diabetes perceived their conditions to be more severe. Onequarter $(25.1 \%)$ of the variation in perceived disease severity was explained by these six significant predictors.

Greater knowledge about the index medication was related to greater patient engagement in their care $(\beta=0.521)$, greater information-seeking tendencies $(\beta=0.325)$, more of an internal locus of control $(\beta=0.062)$, and better mental health $(\beta=0.047)$. Close to one-half $(47.7 \%)$ of the variation in knowledge about the index medication was explained by these four predictors.

Greater perceived immunity to side effects was associated with greater patient engagement in their care $(\beta=0.259)$, less information-seeking tendencies $(\beta=-0.242)$, and better mental health $(\beta=0.119)$. Men felt more immune to side effects. As education increased, perceived immunity to side effects increased. Fifteen percent of the variation in perceived immunity to side effects was explained by these five predictors.

More value placed on nutraceuticals was associated with less patient engagement in care $(\beta=-0.415)$, a greater internal locus of control $(\beta=0.209)$, greater informationseeking tendencies $(\beta=0.126)$, and better self-rated health ( $\beta=0.100)$. Younger persons, nonwhites, and respondents with osteoporosis or asthma placed greater value on nutraceuticals compared to those with hypertension. As both education and income increased, value placed on nutraceuticals decreased. Over one-quarter $(28.6 \%)$ of the variation in perceived value of nutraceuticals was explained by these predictors. 
Table 3 Standardized path loadings of path model in predicting intermediate beliefs

\begin{tabular}{|c|c|c|c|c|c|c|c|c|}
\hline \multirow{3}{*}{$\begin{array}{l}\text { Independent } \\
\text { variables }\end{array}$} & \multicolumn{8}{|c|}{ Intermediate beliefs } \\
\hline & \multicolumn{2}{|c|}{$\begin{array}{l}\text { Perceived disease } \\
\text { severity }\end{array}$} & \multicolumn{2}{|l|}{$\begin{array}{l}\text { Patient } \\
\text { knowledge }\end{array}$} & \multicolumn{2}{|c|}{$\begin{array}{l}\text { Perceived side-effect } \\
\text { immunity }\end{array}$} & \multicolumn{2}{|c|}{$\begin{array}{l}\text { Perceived value of } \\
\text { nutraceuticals }\end{array}$} \\
\hline & Standardized $\beta$ & SE & Standardized $\beta$ & SE & Standardized $\beta$ & SE & Standardized $\beta$ & SE \\
\hline Patient engagement & $0.254^{\ddagger}$ & 0.029 & $0.52 I^{\ddagger}$ & 0.023 & $0.259^{\ddagger}$ & 0.030 & $-0.415^{\ddagger}$ & 0.026 \\
\hline Health information seeking & $0.122^{\ddagger}$ & 0.028 & $0.325^{\ddagger}$ & 0.026 & $-0.242^{\ddagger}$ & 0.030 & $0.126^{\ddagger}$ & 0.029 \\
\hline Internal health locus of control & NS & NS & $0.062^{ \pm}$ & 0.024 & NS & NS & $0.209 \ddagger$ & 0.026 \\
\hline Self-rated health & $-0.262^{\ddagger}$ & 0.030 & NS & NS & NS & NS & $0.100^{\ddagger}$ & 0.028 \\
\hline Mental health & $-0.112^{\ddagger}$ & 0.030 & $0.047^{*}$ & 0.021 & $0.119^{\ddagger}$ & 0.029 & NS & NS \\
\hline Age & NS & NS & NS & NS & NS & NS & $-0.084^{ \pm}$ & 0.025 \\
\hline Female & NS & NS & NS & NS & $-0.11 I^{\ddagger}$ & 0.027 & NS & NS \\
\hline White race & NS & NS & NS & NS & NS & NS & $-0.053^{*}$ & 0.025 \\
\hline Education & $-0.105^{\ddagger}$ & 0.027 & NS & NS & $0.126^{\ddagger}$ & 0.028 & $-0.083^{ \pm}$ & 0.028 \\
\hline Income & NS & NS & NS & NS & NS & NS & $-0.122^{\ddagger}$ & 0.029 \\
\hline Asthma & $-0.074^{*}$ & 0.031 & NS & NS & NS & NS & $0.060 *$ & 0.026 \\
\hline Diabetes & $0.130^{\ddagger}$ & 0.026 & NS & NS & NS & NS & NS & NS \\
\hline Lipid & NS & NS & NS & NS & NS & NS & NS & NS \\
\hline Osteoporosis & $-0.103^{\ddagger}$ & 0.029 & NS & NS & NS & NS & $0.128^{\ddagger}$ & 0.025 \\
\hline Other CVD & $0.094^{\ddagger}$ & 0.026 & NS & NS & NS & NS & NS & NS \\
\hline R square for model & $0.25 \mathrm{I}$ & 0.023 & 0.477 & 0.025 & 0.151 & 0.020 & 0.286 & 0.024 \\
\hline
\end{tabular}

Notes: ${ }^{*} P<0.001 ;{ }^{ \pm}<0.01 ; * P<0.05$; goodness of model fit: $P$-values listed in parentheses; estimator $=$ MLR; 127 free parameters; Chi-square $=248.122$ (df $\left.=121\right)$ with $P$-value $<0.000 \mathrm{I} ; \mathrm{CFI}=0.973 ; \mathrm{RMSEA}=0.03 \mathrm{I} ; 90 \% \mathrm{Cl}=(0.026,0.037) ; \mathrm{SRMR}=0.032$.

Abbreviations: CVD, cardiovascular disease; NS, nonsignificant; SE, standard error; MLR, maximum likelihood with robust standard errors; CFI, comparative fit index; RMSEA, root mean square error of approximation; SRMR, standardized root mean square residual.

Determinants of the more distal generic beliefs are presented in Table 4. The more distal generic beliefs were predominately influenced by age and disease. Older adults and respondents with asthma were more engaged in their care compared to responders with hypertension $\left(\mathrm{R}^{2}=0.037\right)$. Greater information-seeking tendency was associated with female gender, more education, older age, and having asthma or other CVD compared to hypertension $\left(\mathrm{R}^{2}=0.077\right)$. Internal locus of control was associated with less education and nonwhite race $\left(\mathrm{R}^{2}=0.014\right)$. Better self-rated health was associated with higher income, older age, and a lower likelihood of other CVD or diabetes compared to hypertension $\left(\mathrm{R}^{2}=0.121\right)$. Finally, better mental health was associated with older age and higher income $\left(\mathrm{R}^{2}=0.107\right)$.

\section{Discussion}

Over the past 40 years, research on the determinants of medication adherence has gradually shifted from a focus on generic health beliefs to beliefs specific to a treatment and a disease. The Necessity-Concerns Framework ${ }^{6}$ and Proximal-Distal Continuum ${ }^{9}$ are two frameworks that hold that medication adherence is more powerfully explained by treatment-specific than by generic beliefs. Generic beliefs, in turn, are useful in understanding the determinants of diseasespecific beliefs. To the best of the authors' knowledge, this is the first study that has concurrently modeled the predictors of treatment-specific, proximal medication beliefs: perceived need for medications, perceived medication concerns, and perceived medication affordability.

Numerous hypotheses were tested in the SEM modeling of the proximal-distal continuum. However, only a few components of the proximal-distal continuum consistently emerged as statistically-significant predictors with relatively large path coefficients (perceived disease severity, patient knowledge, perceived side-effect immunity, perceived value of nutraceuticals, and patient engagement). These five variables are also the most clinically mutable beliefs and skills in the proximal-distal continuum. Because so few studies have studied the determinants of treatmentspecific beliefs, we contextualize these results largely with past research on medication adherence and discuss their implications for adherence communication and adherence interventions.

Three of the intermediate, independent variables perceived disease severity, knowledge about the index medication, and perceived value of nutraceuticals - were significantly associated with all three proximal adherence drivers. Perceived disease severity - or the potential for a condition to cause physical, mental or psychosocial harm is a significant component of most social-cognitive models of medication taking. ${ }^{2}$ Consistent with past research, ${ }^{18-21,76,77}$ perceived disease severity was a significant predictor of the 


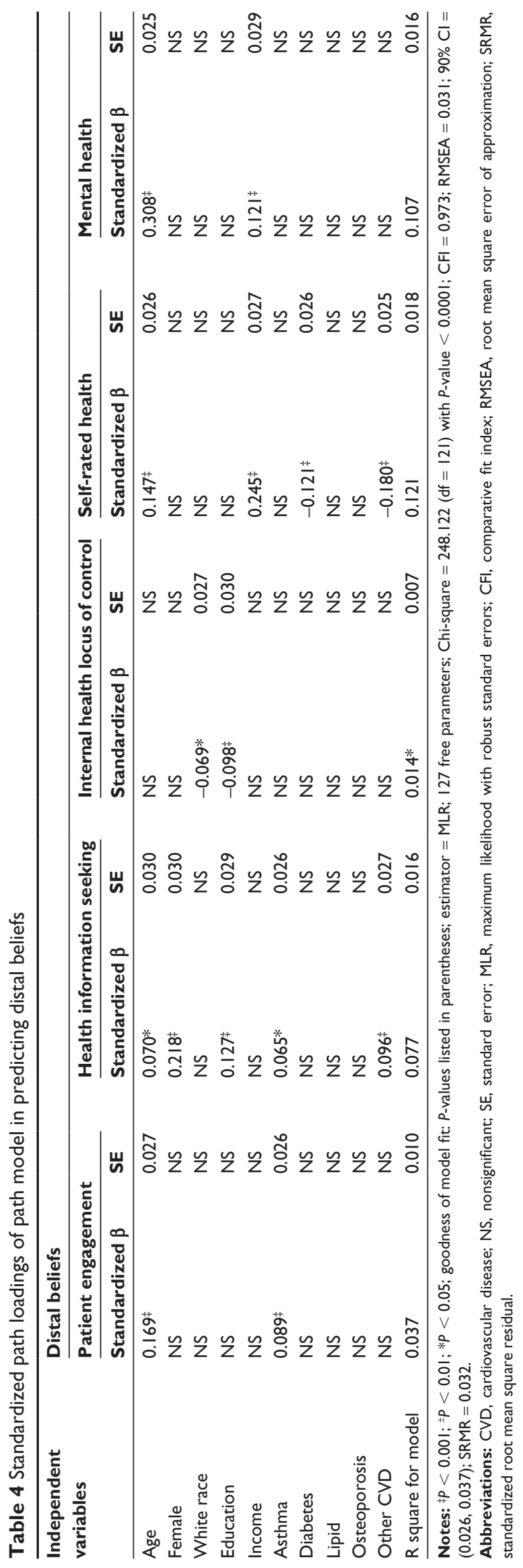

three proximal treatment beliefs, but particularly of perceived need for medications. Patients who perceive their disease to be more severe may appreciate the long-term value of therapy, thus strengthening their intrinsic commitment to medication taking. Patients who perceive their disease to be more severe might be taking multiple medications, thereby making medications less affordable and raising concerns about medication side effects and medication interactions. Greater disease severity has been directly linked to improved medication adherence in numerous studies ${ }^{78-82}$ including a meta-analysis. ${ }^{83}$ Lack of perceived disease severity was cited as a reason for both medication nonfulfillment and nonpersistence in a study of US adults with chronic disease. ${ }^{62}$ Patients need to understand the severity of their condition in order to internalize the rationale for therapy and develop ego commitment to the medication. Health care providers are uniquely qualified to convey to patients the potential severity of their conditions as well as short- and long-term consequences of undertreated or untreated chronic disease. Educational-based adherence interventions should explicitly address disease severity as a content area and assess patient understanding using well-established, patient-centered communication techniques.

In this study, patients with more knowledge about the index medication had significantly greater commitment to (need for) the medication, fewer medication concerns, and greater perceived medication affordability. The largest effect was observed for perceived need for the medication. Patient knowledge has been positively linked with medication adherence in many studies..$^{51,84-92}$ Information/knowledge is one of the troika of adherence drivers in two adherence conceptual frameworks - the Information-Motivation-Behavioral Skills model $^{7}$ and the Information-Motivation-Strategy model. ${ }^{8}$ Lack of knowledge about the disease and/or prescribed therapy has been reported by patients as a reason for medication nonfulfillment or nonpersistence. ${ }^{93-96}$

Both qualitative $\mathrm{e}^{97-101}$ and quantitative ${ }^{102-106}$ research has revealed that many patients lack knowledge about their diagnosed conditions, the potential severity of their conditions, and the consequences of lack of treatment. Patients also frequently report a lack of information about newly prescribed medications. ${ }^{43,102,103,107-116}$ Without sufficient knowledge about their condition, its potential severity, and the rationale for the prescribed medication, many patients may find it difficult to identify with (be ego involved with) the diagnosis and therapy and to accept therapy with a sense of autonomous choice. When uncertainty and ambiguity are high, people tend to pessimistically evaluate the risk and benefits of therapy. ${ }^{117}$ 
Thus, lack of information and knowledge about the diagnosed condition and the prescribed therapy can exacerbate patients' uncertainty and ambivalence about prescription medications and can inhibit their internalization of their condition as chronic in nature.

Past educational/knowledge-based adherence interventions have tended to have small effect sizes. ${ }^{118}$ This finding may be due to education and knowledge being operationalized and delivered differently across studies (eg, as disease knowledge, risk-factor knowledge, medication knowledge, and/or regimen knowledge) and the possibility that knowledge may more powerfully predict the proximal determinants of adherence - perceived need, concerns, and affordability - than adherence per se. Further, few adherence interventions have involved patients in the design and content of the intervention. Future adherence interventions should be truly patient-centered and involve patients a priori in determining what is needed, how much is needed, for how long, and via what channel. It is plausible that what newly diagnosed heart failure patients require in terms of information may be quantitatively and qualitatively different from what breast cancer patients newly prescribed adjuvant hormonal therapy need and prefer. Future adherence interventions should conceptualize knowledge in a multifactorial sense and deliver it longitudinally via a variety of channels and settings. ${ }^{119}$

Many past knowledge-based adherence interventions have been of short duration with only a handful or less of interventional touch points. Future adherence interventions should focus on the first two months of therapy, when the risk of nonpersistence is greatest. Multiple interventional touch points can reinforce learning and help minimize uncertainty. Disease knowledge (etiology, severity, course, and sequelae) and medication knowledge (rationale, duration of therapy, alternative therapies, risks and benefits, and consequences of nonadherence) need to be communicated in health-literacy appropriate ways. Such knowledge could be delivered with patient-centered decision aids or tools that attempt to present unbiased and complete information about the potential benefits and downsides of treatment choices. ${ }^{120}$ The promise of patient-centered decision aids for prescription medications lies in the hope that, through their use, providers will be preparing patients for treatment and involving them in the treatment process. Patients may more readily and consistently accept treatment if they feel the decision to start therapy is their choice rather than the provider's directive. ${ }^{121}$ Finally, it is important to underscore the difference between information/knowledge and patient understanding. Patients can only do what they understand. ${ }^{8}$ Numerous patient-centered techniques are available to gauge patient understanding, such as "teach-back,"122 "ask-tellask," ${ }^{123}$ and "elicit-provide-elicit." ${ }^{124}$ These techniques could not only be used in adherence interventions but in routine clinical practice as well at the time of prescribing. In one study, physicians trained in ask-tell-ask were able to successfully employ the technique without statistically increasing the median visit length. ${ }^{125}$

A novel finding from this study is that respondents who placed more value on nutraceuticals (vitamins, supplements, and minerals) had lower perceived need for medications, more medication concerns, and less perceived medication affordability. Some adults believe over-the-counter and herbal remedies are less risky than prescription medications and that they are natural, safe, familiar, and can be used with less risk. ${ }^{126-128}$ Gascon $^{100}$ found that there was greater confidence in herbal or natural remedies than in prescription medicines to treat hypertension. Other research has found use of complementary and alternative medicine (CAM) to be associated with suboptimal medication-effectiveness beliefs $^{129}$ and worse medication adherence. ${ }^{130-134}$ Favorable attitude toward CAM has been reported to be associated with worse adherence intentions. ${ }^{135}$ Thus, some adults may be substituting pharmaceuticals with nutraceuticals.

An uncertainty lens helps to explain why some patients migrate toward nutraceuticals and alternative medicine for the self-management of chronic disease - they are viewed as doing something good for oneself ("natural" remedies) and as actions involving little risk and little threat to the status quo. Internet website and print communications abound with advertisements that claim to treat or cure chronic disease naturally. Past research has shown that providers are not proactive in discussing nutraceuticals and CAM, ${ }^{131,136}$ and that patients do not proactively disclose their nutraceutical and CAM use to their providers. ${ }^{137,138}$ Physicians, pharmacists, and interventionists should proactively address use of nutraceuticals with patients and communicate their relative clinical efficacy for the treatment of chronic disease compared to prescription medications. Future research should better understand the role of nutraceuticals specifically, and CAM generally, in patients' adherence decisions.

Perceived side-effect immunity was a significant predictor of perceived need and perceived concerns but not affordability. Perceived side-effect immunity was the most important predictor of perceived medication concerns. Other research has linked perceived sensitivity to side effects with enhanced medication concerns. ${ }^{6,77}$ Fear of side effects and 
perceived side-effect susceptibility have been documented in the literature as reasons for medication nonadherence

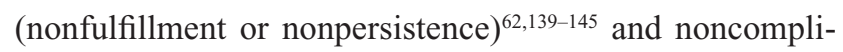
ance (usage deviations). ${ }^{146}$ Little is known about how or why patients come to feel susceptible to side effects. However, research has documented that patients report significant unmet need for side-effect information. ${ }^{10,147-149}$ Physicians express concern that disclosure of side-effect information will increase patients' report and/or experience of side effects through the effect of suggestability. ${ }^{150-154}$ However, extant research has refuted this line of reasoning: side-effect forewarning through verbal or written information has not been shown to increase reports of side effects. ${ }^{155-161}$ On the contrary, patients have relayed that, armed with information about side effects, they would be less likely to become alarmed should a side effect occur and would have fewer concerns about them. ${ }^{162-164}$ In one study, patients reported that detailed disclosure about side effects would make them feel more confident in the physician (94\%), more likely to adhere to treatment (91\%), and more confident in the medication $(82 \%) .{ }^{150}$

Unaddressed medication concerns and fear of side effects can intensify patients' uncertainty especially when the potential benefits of medication therapy have not been appropriately communicated and when potential benefits do not occur immediately, as with most asymptomatic chronic conditions. Providers should disclose common side effects and create a plan with patients that addresses what they should do should a side effect occur. ${ }^{165}$ Such collaborative communication behaviors are consistent with patient-centered care and shared decision making. Adherence interventionists can employ patient-centered decision aids to communicate both the pros and cons of treatment in a balanced manner.

Our measure of patient engagement assessed patient trust in their provider and patient involvement in their care. In this study, patient engagement was a significant predictor of six of the seven outcomes (all but perceived medication affordability). Patients who were more engaged in their care had a greater perceived need for medications, fewer medication concerns, perceived their disease to be more severe, had more knowledge about the index medication, felt more immune to side effects, and valued nutraceuticals less. The greatest impact was on prescription-medication knowledge. In women with osteoporosis, Schousboe et $\mathrm{al}^{20}$ also found patient engagement to be significantly related to greater perceived need for medications and fewer medication concerns. Two other studies reported patient trust to be associated with better medication beliefs, ${ }^{21,166}$ a finding similar to our observed results. Both patient trust ${ }^{167-171}$ and patient involvement ${ }^{172-174}$ have been demonstrated in past research to be associated with improved medication adherence. Two recent meta-analyses concluded that better physician-patient collaboration ${ }^{175}$ and better physician communication ${ }^{176}$ significantly influence medication adherence.

Patient engagement is a key foundational element of patient-centered care and shared decision making. Past research has shown that patients can be coached to be more proactively involved in their care. ${ }^{177-185}$ Involving patients in medication-therapy decision making may increase their intrinsic motivation and ego involvement in treatment. A simple way to engage patients is to ask whether they are ready to commit to therapy. Patients' expression of uncertainty or ambivalence is a marker for unresolved concerns or unmet information needs. Patient-centered decision aids for prescription medications may be a cost- and time-effective way of increasing patient engagement in their treatment in both clinical practice and in adherence interventions.

Although numerous hypotheses were tested in the SEM modeling of the proximal-distal continuum, none of the observed results were anomalous. In the vast majority of findings, coefficient signs were in the expected direction. As a predictor variable, the multi-item scale assessing health-information seeking yielded three results that could have plausibly been either positive or negative. Patients with greater health-information seeking tendencies had less perceived need for medications (Table 2), more perceived medication concerns, (Table 2), and less perceived immunity to side effects (Table 3). While health-information seeking was significantly and positively related to greater patient knowledge (Table 3), it is possible that health-information seeking could generate negative or even conflicting information, which could then dampen perceived need, elevate medication concerns, and elevate susceptibility to side effects.

\section{Study strengths and limitations}

There are both strengths and limitations to the study. In terms of strengths, use of the proximal-distal continuum was based upon both conceptual and empirical learning accumulated over the past 40 years. A large, internet-based panel of adults with chronic disease was accessed with representation from 47 of the 50 US states. Most of the multi-item scales were highly internally consistent (range of Cronbach's alpha of 0.76 to 0.97 , median $=0.91$ ). We had a large sample size $(n=1072)$ upon which to test the SEM model.

In terms of limitations, the survey contact rate $(26.5 \%)$ was low. Survey noncontact analysis indicated that persons aged 55 years and older, whites, and those with at least a 
college degree were more likely to be successfully contacted than their respective counterparts. ${ }^{9}$ The obtained internetbased sample was slightly underrepresented by adults with income less than $\$ 25,000$ annually compared to the US adult population. ${ }^{186}$ Also, relative to the US adult population aged 25 years and older, ${ }^{187,188}$ the obtained sample had an underrepresentation of adults with less than a high-school education, an overrepresentation of adults with at least a college degree, and overrepresentation of whites. Because of these demographic differences between the obtained sample and the US general adult population, generalizability of our results to the broader US population may not be appropriate. An Internet panel was used, which also may limit generalizability. The study was cross sectional. As a result of the cross-sectional design, no inferences regarding causality of the elements of the proximal-distal continuum can be made. The study involved adults with self-identified chronic disease. None of the six study conditions were substantiated with medical records. On the other hand, a well-defined, chronic disease panel was accessed and the six conditions were reverified using a separate, independent screener than was used to enroll the Chronic Illness Panel. Only six conditions were studied, although they are highly prevalent in the US adult population. No psychiatric conditions were studied. The array of adherence drivers tested in the proximal-distal continuum was not exhaustive of the 200 putative adherence determinants. ${ }^{189}$ We did not study some adherence determinants included in other research, such as self-efficacy, social support, symptom severity, the experience of side effects, side-effect severity, length of time with the diagnosis, and length of time in treatment with prescription-medication therapy. We only tested the proximal-distal continuum and did not test alternative theoretical models of adherence drivers.

\section{Conclusion}

For decades now, nonadherence has been among the most significant problems facing medical practice. ${ }^{190}$ Nonadherence is a psychosocial marker that issues important to patients were not addressed - that patients have unvoiced uncertainties and ambivalence about their condition and prescribed therapy. In clinical practice, a shroud of silence envelopes the topic of medication adherence: physicians often do not proactively ask about adherence and patients frequently do not tell them when they fail to fill a new prescription or stop therapy on their own. ${ }^{9}$ Thus, patients are largely alone with their doubts and uncertainties. For long-term medication adherence, patients need to autonomously and intrinsically commit to therapy and this is more likely to occur when they are informed (about disease knowledge, disease severity, medication knowledge and rationale, consequences of nonadherence, and side effects), understand, and are motivated (engaged in their care, perceive a need for medication, and believe the benefits outweigh the risks). In short, intuitively patient-centered strategies are needed to help patients to know what their condition is, why the medication is needed, how the prescribed therapy may help, and how the benefits may outweigh the risks.

Testing the proximal-distal continuum of adherence drivers sheds light on specific areas where adherence dialogue and enhancement could focus. Our results can help to inform the design of future adherence interventions, as well as the content of patient-education materials and adherence reminder letters. An important learning from testing the proximal-distal continuum is that future adherence interventions need to move from manipulating single adherence barriers to interceding in a multidimensional space. Results also suggest that intervening along the etiological continuum of patient beliefs, states, and skills may more optimally improve adherence than intervening in a single causal space. Interventions that focus on distal beliefs, states, and skills should be deprioritized. Instead of assuming a one-size-fit-all design, future adherence interventions should target persons who are deficit in the proximal determinants of adherence: perceived need for medications, perceived medication concerns, and perceived medication affordability. In addition, it should be possible to target patients or tailor interventions using the most important sociomedical predictors identified in this study: perceived disease severity, patient knowledge, perceived side-effect immunity, perceived value of nutraceuticals, and patient engagement.

\section{Disclosure}

The authors declare no conflicts of interest in this work.

\section{References}

1. Brawley LR, Culos-Reed SN. Studying adherence to therapeutic regimens: overview, theories, recommendations. Control Clin Trials. 2000;21(Suppl 5):S156-S163.

2. Becker MH, Maiman LA. Sociobehavioral determinants of compliance with health and medical care recommendations. Med Care. 1975;13(1):10-24.

3. Fumaz CR, Muñoz-Moreno JA, Moltó J, et al. Sustained antiretroviral treatment adherence in survivors of the pre-HAART era: attitudes and beliefs. AIDS Care. 2008;20(7):796-805.

4. Farmer A, Kinmonth AL, Sutton S. Measuring beliefs about taking hypoglycaemic medication among people with Type 2 diabetes. Diabet Med. 2006;23(3):265-270.

5. Johnson SS, Driskell MM, Johnson JL, et al. Transtheoretical model intervention for adherence to lipid-lowering drugs. Dis Manag. 2006;9(2):102-114. 
6. Horne R. Representations of medications and treatment: advances in theory and measurement. In: Petrie KJ, Weinman JA, editors. Perceptions of Health and Illness. Amsterdam: Harwood; 1997:155-188.

7. Amico KR, Toro-Alfonso J, Fisher JD. An empirical test of the information, motivation and behavioral skills model of antiretroviral therapy adherence. AIDS Care. 2005;17(6):661-673.

8. DiMatteo MR, Haskard-Zolnierek KB, Martin LR. Improving patient adherence: a three-factor model to guide practice. Health Psychol Rev. 2012;6(1):74-91.

9. McHorney CA. The Adherence Estimator: a brief, proximal screener for patient propensity to adhere to prescription medications for chronic disease. Curr Med Res Opin. 2009;25(1):215-238.

10. Gardner EM, Burman WJ, Maravi ME, Davidson AJ. Selective drug taking during combination antiretroviral therapy in an unselected clinic population. J Acquir Immune Defic Syndr. 2005;40(3):294-300.

11. Ho PM, Spertus JA, Masoudi FA, et al. Impact of medication therapy discontinuation on mortality after myocardial infarction. Arch Intern Med. 2006;166(17):1842-1847.

12. Lo Re V 3rd, Teal V, Localio AR, Amorosa VK, Kaplan DE, Gross R. Relationship between adherence to hepatitis $\mathrm{C}$ virus therapy and virologic outcomes: a cohort study. Ann Intern Med. 2011;155(6):353-360.

13. Krigsman K, Nilsson JL, Ring L. Adherence to multiple drug therapies: refill adherence to concomitant use of diabetes and asthma/ COPD medication. Pharmacoepidemiol Drug Saf. 2007;16(10): 1120-1128.

14. Piette JD, Heisler M, Ganoczy D, McCarthy JF, Valenstein M. Differential medication adherence among patients with schizophrenia and comorbid diabetes and hypertension. Psychiatr Serv. 2007;58(2):207-212.

15. Agarwal S, Tang SS, Rosenberg N, et al. Does synchronizing initiation of therapy affect adherence to concomitant use of antihypertensive and lipid-lowering therapy? Am J Ther. 2009;16(2):119-126.

16. Benner JS, Chapman RH, PetrillaAA, Tang SS, Rosenberg N, Schwartz JS. Association between prescription burden and medication adherence in patients initiating antihypertensive and lipid-lowering therapy. Am J Health Syst Pharm. 2009;66(16):1471-1477.

17. Yood RA, Mazor KM, Andrade SE, Emani S, Chan W, Kahler KH. Patient decision to initiate therapy for osteoporosis: the influence of knowledge and beliefs. J Gen Intern Med. 2008;23(11):1815-1821.

18. Horne R, Weinman J. Self-regulation and self-management in asthma: exploring the role of illness perceptions and treatment beliefs in explaining non-adherence to preventer medication. Psychol Health. 2002;17(1):17-32.

19. Nicklas LB, Dunbar M, Wild M. Adherence to pharmacological treatment of non-malignant chronic pain: the role of illness perceptions and medication beliefs. Psychol Health. 2010;25(5):1-15.

20. Schousboe JT, Davison ML, Dowd B, Thiede Call K, Johnson P, Kane RL. Predictors of patients' perceived need for medication to prevent fracture. Med Care. 2011;49(3):273-280.

21. Baloush-Kleinman V, Levine SZ, Roe D, Shnitt D, Weizman A, Poyurovsky M. Adherence to antipsychotic drug treatment in earlyepisode schizophrenia: a six-month naturalistic follow-up study. Schizophr Res. 2011;130(1-3):176-181.

22. Ackerson K, Preston SD. A decision theory perspective on why women do or do not decide to have cancer screening: systematic review. $J A d v$ Nurs. 2009;65(6):1130-1140.

23. Oggins J. Notions of HIV and medication among multiethnic people living with HIV. Health Soc Work. 2003;28(1):53-62.

24. DiMatteo MR. Variations in patients' adherence to medical recommendations: a quantitative review of 50 years of research. Med Care. 2004;42(3):200-209.

25. Treharne GJ, Lyons AC, Kitas GD. Medication adherence in rheumatoid arthritis: effects of psychosocial factors. Psychol Health Med. 2004;9(3):337-349.

26. Byrne M, Walsh J, Murphy AW. Secondary prevention of coronary heart disease: patient beliefs and health-related behaviour. J Psychosom Res. 2005;58(5):403-415.
27. Grunfeld EA, Hunter MS, Sikka P, Mittal S. Adherence beliefs among breast cancer patients taking tamoxifen. Patient Educ Couns. 2005;59(1): 97-102.

28. Sud A, Kline-Rogers EM, Eagle KA, et al. Adherence to medications by patients after acute coronary syndromes. Ann Pharmacother. 2005;39(11):1792-1797.

29. Horne R, Cooper V, Gellaitry G, Date HL, Fisher M. Patients' perceptions of highly active antiretroviral therapy in relation to treatment uptake and adherence: the utility of the necessity-concerns framework. J Acquir Immune Defic Syndr. 2007;45(3):334-341.

30. Gonzalez JS, Penedo FJ, Llabre MM, et al. Physical symptoms, beliefs about medications, negative mood, and long-term HIV medication adherence. Ann Behav Med. 2007;34(1):46-55.

31. Moshkovska T, Stone MA, Clatworthy J, et al. An investigation of medication adherence to 5-aminosalicylic acid therapy in patients with ulcerative colitis, using self-report and urinary drug excretion measurements. Aliment Pharmacol Ther. 2009;30(11-12):1118-1127.

32. Bucks RS, Hawkins K, Skinner TC, Horn S, Seddon P, Horne R. Adherence to treatment in adolescents with cystic fibrosis: the role of illness perceptions and treatment beliefs. J Pediatr Psychol. 2009; 34(8):893-902.

33. Clatworthy J, Bowskill R, Parham R, Rank T, Scott J, Horne R. Understanding medication non-adherence in bipolar disorders using a Necessity-Concerns Framework. J Affect Disord. 2009;116(1-2): $51-55$.

34. Schousboe JT, Dowd BE, Davison ML, Kane RL. Association of medication attitudes with non-persistence and non-compliance with medication to prevent fractures. Osteoporos Int. 2010;21(11):1899-1909.

35. Griva K, Davenport A, Harrison M, Newman SP. Non-adherence to immunosupressive medications in kidney transplantation: intent vs forgetfulness and clinical markers of medication intake. Ann Behav Med. 2012;44(1):85-93.

36. Ruppar TM, Dobbels F, De Geest S. Medication beliefs and antihypertensive adherence among older adults: a pilot study. Geriatr Nurs. 2012;33(2):89-95.

37. Schoenthaler AM, Schwartz BS, Wood C, Stewart WF. Patient and physician factors associated with adherence to diabetes medications. Diabetes Educ. 2012;38(3):397-408.

38. Maidment R, Livingston G, Katona C. Just keep taking the tablets: adherence to antidepressant treatment in older people in primary care. Int J Geriatr Psychiatry. 2002;17(8):752-757.

39. Ayalon L, Areán PA, Alvidrez J. Adherence to antidepressant medications in black and Latino elderly patients. Am J Geriatr Psychiatry. 2005;13(7):572-580

40. Gellaitry G, Cooper V, Davis C, Fisher M, Date HL, Horne R. Patients' perception of information about HAART: impact on treatment decisions. AIDS Care. 2005;17(3):367-376.

41. Carr AJ, Thompson PW, Cooper C. Factors associated with adherence and persistence to bisphosphonate therapy in osteoporosis: a crosssectional survey. Osteoporos Int. 2006;17(11):1638-1644.

42. Hunot VM, Horne R, Leese MN, Churchill RC. A cohort study of adherence to antidepressants in primary care: the influence of antidepressant concerns and treatment preferences. Prim Care Companion J Clin Psychiatry. 2007;9(2):91-99.

43. Mann DM, Allegrante JP, Natarajan S, Halm EA, Charlson M. Predictors of adherence to statins for primary prevention. Cardiovasc Drugs Ther. 2007;21(4):311-316.

44. Aikens JE, Piette JD. Diabetic patients' medication underuse, illness outcomes, and beliefs about antihyperglycemic and antihypertensive treatments. Diabetes Care. 2009;32(1):19-24.

45. Daleboudt GM, Broadbent E, McQueen F, Kaptein AA. Intentional and unintentional treatment nonadherence in patients with systemic lupus erythematosus. Arthritis Care Res (Hoboken). 2011;63(3): $342-350$.

46. O’Carroll R, Whittaker J, Hamilton B, Johnston M, Sudlow C, Dennis M. Predictors of adherence to secondary preventive medication in stroke patients. Ann Behav Med. 2011;41(3):383-390. 
47. Solomon DH, Brookhart MA, Tsao P, et al. Predictors of very low adherence with medications for osteoporosis: towards development of a clinical prediction rule. Osteoporos Int. 2011;22(6):1737-1743.

48. Patel SC, Spaeth GL. Compliance in patients prescribed eyedrops for glaucoma. Ophthalmic Surg. 1995;26(3):233-236.

49. Brown CM, Segal R. The effects of health and treatment perceptions on the use of prescribed medication and home remedies among African American and white American hypertensives. Soc Sci Med. 1996;43(6):903-917.

50. Goeman DP, Aroni RA, Stewart K, et al. Patients' views of the burden of asthma: a qualitative study. Med J Aust. 2002;177(6):295-299.

51. Kamatari M, Koto S, Ozawa N, et al. Factors affecting long-term compliance of osteoporotic patients with bisphosphonate treatment and QOL assessment in actual practice: alendronate and risedronate. J Bone Miner Metab. 2007;25(5):302-309.

52. Friedman DS, Hahn SR, Gelb L, et al. Doctor-patient communication, health-related beliefs, and adherence in glaucoma: results from the Glaucoma Adherence and Persistency Study. Ophthalmology. 2008;115(8):1320-1327.

53. Wu JR, Moser DK, Chung ML, Lennie TA. Predictors of medication adherence using a multidimensional adherence model in patients with heart failure. J Card Fail. 2008;14(7):603-614.

54. Kim E, Gupta S, Bolge S, Chen CC, Whitehead R, Bates JA. Adherence and outcomes associated with copayment burden in schizophrenia: a cross-sectional survey. J Med Econ. 2010;13(2):185-192.

55. Marshall IJ, Wolfe CD, Mckevitt C. Lay perspectives on hypertension and drug adherence: systematic review of qualitative research. $B M J$. 2012;345:e3953.

56. National Center for Health Statistics. Health, United States, 2010: With Special Feature on Death and Dying. Hyattsville: US Department of Health and Human Services; 2011.

57. DeVol R, Bedroussian A, Charuworn A, et al. An Unhealthy America: The Economic Burden of Chronic Disease - Charting a New Course to Save Lives and Increase Productivity and Economic Growth. Santa Monica: The Milken Institute; 2007.

58. The American Association for Public Opinion Research. Standard Definitions: Final Dispositions of Case Codes and Outcome Rates for Surveys. Lenexa: AAPOR; 2008.

59. Wallston KA. Multidimensional health locus of control (MHLC) scales [updated June 15, 2007]. Available from: http://www.vanderbilt.edu/ nursing/kwallston/mhlcscales.htm. Accessed January 15, 2008.

60. Ware JE, Sherbourne CD. The MOS 36-item short-form health survey (SF-36): I. Conceptual framework and item selection. Med Care. 1992;30(6):473-483.

61. McHorney CA, Gadkari AS. Individual patients hold different beliefs to prescription medications to which they persist vs nonpersist and persist vs nonfulfill. Patient Prefer Adherence. 2010;4:187-195.

62. McHorney CA, Spain CV. Frequency of and reasons for medication non-fulfillment and non-persistence among American adults with chronic disease in 2008. Health Expect. 2011;14(3): 307-320.

63. Piette JD, Beard A, Rosland AM, McHorney CA. Beliefs that influence cost-related medication non-adherence among the "haves" and "have nots" with chronic diseases. Patient Prefer Adherence. 2011;5: 389-396.

64. Gadkari AS, McHorney CA. Unintentional non-adherence to chronic prescription medications: how unintentional is it really? BMC Health Serv Res. 2012. Epub June 14.

65. Likert R. A technique for the measurement of attitudes. Arch Psychol. 1932;140:5-55.

66. Wright S. Correlation and causation. J Agric Res. 1921;20:557-585.

67. Wright S. The method of path coefficients. Ann Math Stat. 1934;5:161-215.

68. Wright S. Path coefficients and path regressions: alternative or complementary concepts. Biometrics. 1960;16:189-202.

69. Bollen KA. Structural Equations with Latent Variables, New York: Wiley \& Sons; 1989.
70. Muthün L, Müthen B. Mplus User's Guide. 6th ed. Los Angeles: Muthen \& Muthen; 1998-2007.

71. Hu L, Bentler PM. Cutoff criteria for fit indexes in covariance structure analysis: conventional criteria versus new alternatives. Structural Equation Modeling. 1999;6:1-55.

72. Kline R. Principles and Practice of Structural Equation Modeling. 3rd ed. New York: Guilford; 2010.

73. Bentler PM, Bonett DG. Significance tests and goodness of fit in the analysis of covariance structures. Psychol Bulletin. 1980;88:588-606.

74. Jöreskog K, Sörbom D. LISREL 8: User's Reference Guide. Chicago: Scientific Software Int; 1996.

75. McIntosh C. Rethinking fit assessment in structural equation modelling: A commentary and elaboration on Barrett. Pers Individ Dif. 2007;42:859-867.

76. Aikens JE, Nease DE Jr, Klinkman MS. Explaining patients' beliefs about the necessity and harmfulness of antidepressants. Ann Fam Med. 2008;6(1):23-29.

77. Horne R, Parham R, Driscoll R, Robinson A. Patients' attitudes to medicines and adherence to maintenance treatment in inflammatory bowel disease. Inflamm Bowel Dis. 2009;15(6):837-844.

78. Sirey JA, Bruce ML, Alexopoulos GS, Perlick DA, Friedman SJ, Meyers BS. Stigma as a barrier to recovery: Perceived stigma and patient-rated severity of illness as predictors of antidepressant drug adherence. Psychiatr Serv. 2001;52(12):1615-1620.

79. De Smet BD, Erickson SR, Kirking DM. Self-reported adherence in patients with asthma. Ann Pharmacother. 2006;40(3):414-420.

80. Bardel A, Wallander MA, Svärdsudd K. Factors associated with adherence to drug therapy: a population-based study. Eur J Clin Pharmacol. 2007;63(3):307-314.

81. Bolman C, Arwert TG, Völlink T. Adherence to prophylactic asthma medication: habit strength and cognitions. Heart Lung. 2011;40(1):63-75

82. Unni E, Farris KB. Determinants of different types of medication nonadherence in cholesterol lowering and asthma maintenance medications: a theoretical approach. Patient Educ Couns. 2011;83(3):382-390.

83. DiMatteo MR, Haskard KB, Williams SL. Health beliefs, disease severity, and patient adherence: a meta-analysis. Med Care. 2007;45(6):521-528.

84. Viller F, Guillemin F, Briancon S, Moum T, Suurmeijer T, van den Heuvel W. Compliance to drug treatment of patients with rheumatoid arthritis: a 3 year longitudinal study. J Rheumatol. 1999;26(10): 2114-2122.

85. Kim EY, Han HR, Jeong S, et al. Does knowledge matter? Intentional medication nonadherence among middle-aged Korean Americans with high blood pressure. J Cardiovasc Nurs. 2007;22(5):397-404.

86. Ringe JD, Christodoulakos GE, Mellström D, et al. Patient compliance with alendronate, risedronate and raloxifene for the treatment of osteoporosis in postmenopausal women. Curr Med Res Opin. 2007;23(11):2677-2687.

87. Morisky DE, Ang A, Krousel-Wood M, Ward HJ. Predictive validity of a medication adherence measure in an outpatient setting. J Clin Hypertens (Greenwich). 2008;10(5):348-354.

88. Wells K, Pladevall M, Peterson EL, et al. Race-ethnic differences in factors associated with inhaled steroid adherence among adults with asthma. Am J Respir Crit Care Med. 2008;178(12):1194-1201.

89. Bermejo F, López-San Román A, Algaba A, et al. Factors that modify therapy adherence in patients with inflammatory bowel disease. J Crohns Colitis. 2010;4(4):422-426.

90. Son YJ, Kim HG, Kim EH, Choi S, Lee SK. Application of support vector machine for prediction of medication adherence in heart failure patients. Healthc Inform Res. 2010;16(4):253-259.

91. Al-Qazaz HK, Sulaiman SA, Hassali MA, et al. Diabetes knowledge, medication adherence and glycemic control among patients with type 2 diabetes. Int J Clin Pharm. 2011;33(6):1028-1035.

92. Bowry AD, Shrank WH, Lee JL, Stedman M, Choudhry NK. A systematic review of adherence to cardiovascular medications in resource-limited settings. J Gen Intern Med. 2011;26(12):1479-1491. 
93. Parashos IA, Xiromeritis K, Zoumbou V, Stamouli S, Theodotou R. The problem of non-compliance in schizophrenia: opinions of patients and their relatives. A pilot study. Int J Psychiatry Clin Pract. 2000;4(2):147-150.

94. Mansur AP, Mattar AP, Tsubo CE, Simão DT, Yoshi FR, Daci K. Prescription and adherence to statins of patients with coronary artery disease and hypercholesterolemia. Arq Bras Cardiol. 2001;76(2): 111-118.

95. Kripalani S, Henderson LE, Jacobson TA, Vaccarino V. Medication use among inner-city patients after hospital discharge: patient-reported barriers and solutions. Mayo Clin Proc. 2008;83(5):529-535.

96. Sajatovic M, Levin J, Fuentes-Casiano E, Cassidy KA, Tatsuoka C, Jenkins JH. Illness experience and reasons for nonadherence among individuals with bipolar disorder who are poorly adherent with medication. Compr Psychiatry. 2011;52(3):280-287.

97. Tolmie EP, Lindsay GM, Kerr SM, Brown MR, Ford I, Gaw A. Patients' perspectives on statin therapy for treatment of hypercholesterolaemia: a qualitative study. Eur J Cardiovasc Nurs. 2003;2(2):141-149.

98. Bajramovic J, Emmerton L, Tett SE. Perceptions around concordance - focus groups and semi-structured interviews conducted with consumers, pharmacists and general practitioners. Health Expect. 2004;7(3):221-234.

99. Bollini P, Tibaldi G, Testa C, Munizza C. Understanding treatment adherence in affective disorders: a qualitative study. J Psychiatr Ment Health Nurs. 2004;11(6):668-674.

100. Gascón JJ, Sánchez-Ortuño M, Llor B, Skidmore D, Saturno PJ; for Treatment Compliance in Hypertension Study Group. Why hypertensive patients do not comply with the treatment: results from a qualitative study. Fam Pract. 2004;21(2):125-130.

101. Morecroft C, Cantrill J, Tully MP. Patients' evaluation of the appropriateness of their hypertension management--a qualitative study. Res Social Adm Pharm. 2006;2(2):186-211.

102. Barber N, Parsons J, Clifford S, Darracott R, Horne R. Patients' problems with new medication for chronic conditions. Qual Saf Health Care. 2004;13(3):172-175.

103. Neame R, Hammond A, Deighton C. Need for information and for involvement in decision making among patients with rheumatoid arthritis: a questionnaire survey. Arthritis Rheum. 2005;53(2): 249-255.

104. Mochari H, Ferris A, Adigopula S, Henry G, Mosca L. Cardiovascular disease knowledge, medication adherence, and barriers to preventive action in a minority population. Prev Cardiol. 2007;10(4):190-195.

105. Shiri C, Srinivas SC, Futter WT, Radloff SE. The role of insight into and beliefs about medicines of hypertensive patients. Cardiovasc $J$ Afr. 2007;18(6):353-357.

106. Hobbs FD, Erhardt LR, Rycroft C; for From the Heart study Investigators. The From The Heart study: a global survey of patient understanding of cholesterol management and cardiovascular risk, and physician-patient communication. Curr Med Res Opin. 2008;24(5):1267-1278.

107. Ridout S, Waters WE, George CF. Knowledge of and attitudes to medicines in the Southampton community. Br J Clin Pharmacol. 1986;21(6):701-712.

108. Enlund H, Vainio K, Wallenius S, Poston JW. Adverse drug effects and the need for drug information. Med Care. 1991;29(6):558-564.

109. McCormack PM, Lawlor R, Donegan C, et al. Knowledge and attitudes to prescribed drugs in young and elderly patients. Ir Med J. 1997;90(1):29-30.

110. Morris LA, Tabak ER, Gondek K. Counseling patients about prescribed medication: 12-year trends. Med Care. 1997;35(10):996-1007.

111. Barat I, Andreasen F, Damsgaard EM. Drug therapy in the elderly: what doctors believe and patients actually do. Br J Clin Pharmacol. 2001;51(6):615-622.

112. Sleath B, Wurst K. Patient receipt of, and preferences for receiving, antidepressant information. Int J Pharm Pract. 2002;10(4):235-241.

113. Coulter A. What do patients and the public want from primary care? BMJ. 2005;331(7526):1199-1201.
114. Gray R, Rofail D, Allen J, Newey T. A survey of patient satisfaction with and subjective experiences of treatment with antipsychotic medication. J Adv Nurs. 2005;52(1):31-37.

115. Paton C, Esop R. Patients' perceptions of their involvement in decision making about antipsychotic drug choice as outlined in the NICE guidance on the use of atypical antipsychotics in schizophrenia. JMent Health. 2005;14(3):305-310.

116. Richard C, Lussier MT. Nature and frequency of exchanges on medications during primary care encounters. Patient Educ Couns. 2006;64(1-3):207-216.

117. Han PK, Kobrin SC, Klein WM, Davis WW, Stefanek M, Taplin SH. Perceived ambiguity about screening mammography recommendations: association with future mammography uptake and perceptions. Cancer Epidemiol Biomarkers Prev. 2007;16(3):458-466.

118. Peterson AM, Takiya L, Finley R. Meta-analysis of trials of interventions to improve medication adherence. Am J Health Syst Pharm. 2003;60(7):657-665.

119. Brown MT, Bussell JK. Medication adherence: WHO cares? Mayo Clin Proc. 2011;86(4):304-314.

120. Wilson SR, Strub P, Buist AS, et al. Shared treatment decision making improves adherence and outcomes in poorly controlled asthma. Am J Respir Crit Care Med. 2010;181(6):566-577.

121. Stalmeier PF. Adherence and decision AIDs: a model and a narrative review. Med Decis Making. 2011;31(1):121-129.

122. Oates DJ, Paasche-Orlow MK. Health literacy: communication strategies to improve patient comprehension of cardiovascular health. Circulation. 2009;119(7):1049-1051.

123. Hahn SR. Patient-centered communication to assess and enhance patient adherence to glaucoma medication. Ophthalmology. 2009;116(Suppl 11):S37-S42.

124. Gabbay RA, Durdock K. Strategies to increase adherence through diabetes technology. J Diabetes Sci Technol. 2010;4(3):661-665.

125. Hahn SR, Lipton RB, Sheftell FD, et al. Healthcare provider-patient communication and migraine assessment: results of the American Migraine Communication Study, phase II. Curr Med Res Opin. 2008;24(6):1711-1718.

126. Morgan M. The significance of ethnicity for health promotion: patients use of antihypertensive drugs in inner London. Int J Epidemiol. 1995;24 Suppl 1:S79-S84.

127. Bissell P, Ward PR, Noyce PR. The dependent consumer: reflections on accounts of the risks of non-prescription medicines. Health (London). 2001;5(1):5-30.

128. Lynch N, Berry D. Differences in perceived risks and benefits of herbal, over-the-counter conventional, and prescribed conventional, medicines, and the implications of this for the safe and effective use of herbal products. Complement Ther Med. 2007;15(2):84-91.

129. Jarman CN, Perron BE, Kilbourne AM, Teh CF. Perceived treatment effectiveness, medication compliance, and complementary and alternative medicine use among veterans with bipolar disorder. J Altern Complement Med. 2010;16(3):251-255.

130. Owen-Smith A, Diclemente R, Wingood G. Complementary and alternative medicine use decreases adherence to HAART in HIV-positive women. AIDS Care. 2007;19(5):589-593.

131. Gohar F, Greenfield SM, Beevers DG, Lip GY, Jolly K. Self-care and adherence to medication: a survey in the hypertension outpatient clinic. BMC Complement Altern Med. 2008;8:4.

132. Krousel-Wood MA, Muntner P, Joyce CJ, et al. Adverse effects of complementary and alternative medicine on antihypertensive medication adherence: findings from the cohort study of medication adherence among older adults. J Am Geriatr Soc. 2010;58(1):54-61.

133. Roy A, Lurslurchachai L, Halm EA, Li XM, Leventhal H, Wisnivesky JP. Use of herbal remedies and adherence to inhaled corticosteroids among inner-city asthmatic patients. Ann Allergy Asthma Immunol. 2010;104(2):132-138

134. Dean AJ, Wragg J, Draper J, McDermott BM. Predictors of medication adherence in children receiving psychotropic medication. J Paediatr Child Health. 2011;47(6):350-355. 
135. Villagran M, Hajek C, Zhao X, Peterson E, Wittenberg-Lyles E. Communication and culture: predictors of treatment adherence among Mexican immigrant patients. J Health Psychol. 2012;17(3):443-452.

136. Brown CM, Pena A, Resendiz K. Pharmacists' actions when patients use complementary and alternative medicine with medications: a look at Texas-Mexico border cities. J Am Pharm Assoc (2003). 2011;51(5): 619-622.

137. ChongCA,Diaz-Granados N,HawkerGA, JamalS, Josse RG, CheungAM. Complementary and alternative medicine use by osteoporosis clinic patients. Osteoporos Int. 2007;18(11):1547-1556.

138. Mak JC, Faux S. Use of complementary and alternative medicine by patients with osteoporosis in Australia. Med J Aust. 2010;192(1): 54-55.

139. Leung TN, Haines CJ, Chung TK. Five-year compliance with hormone replacement therapy in postmenopausal Chinese women in Hong Kong. Maturitas. 2001;39(3):195-201.

140. Son H, Park K, Kim SW, Paick JS. Reasons for discontinuation of sildenafil citrate after successful restoration of erectile function. Asian J Androl. 2004;6(2):117-120.

141. Brown KK, Rehmus WE, Kimball AB. Determining the relative importance of patient motivations for nonadherence to topical corticosteroid therapy in psoriasis. J Am Acad Dermatol. 2006;55(4): 607-613.

142. Ulrik CS, Backer V, Søes-Petersen U, Lange P, Harving H, Plaschke PP. The patient's perspective: adherence or non-adherence to asthma controller therapy? J Asthma. 2006;43(9):701-704.

143. van Geffen EC, van Hulten R, Bouvy ML, Egberts AC, Heerdink ER. Characteristics and reasons associated with nonacceptance of selective serotonin-reuptake inhibitor treatment. Ann Pharmacother. 2008;42(2):218-225.

144. Harrison T. Primary non-adherence to statin therapy in an integrated delivery system: patients' perspective. Clin Med Res. 2011;9(3-4): $150-151$.

145. Lakatos PL, Czegledi Z, David G, et al. Association of adherence to therapy and complementary and alternative medicine use with demographic factors and disease phenotype in patients with inflammatory bowel disease. J Crohns Colitis. 2010;4(3):283-290.

146. Buston KM, Wood SF. Non-compliance amongst adolescents with asthma: listening to what they tell us about self-management. Fam Pract. 2000;17(2):134-138.

147. Morris LA. A survey of patients' receipt of prescription drug information. Med Care. 1982;20(6):596-605.

148. Gallup G Jr, Cotugno HE. Preferences and practices of Americans and their physicians in antihypertensive therapy. $A m \mathrm{~J} \mathrm{Med}$. 1986;81(6C):20-24.

149. Davis K, Schoen C, Schoenbaum SC, et al. Mirror, Mirror on the Wall: An Update on the Quality of American Health Care Through the Patient's Lens. New York: The Commonwealth Fund;2006. Available from: http://www.commonwealthfund.org/Publications/ Fund-Reports/2006/Apr/Mirror-Mirror-on-the-Wall-An-Update-onthe-Quality-of-American-Health-Care-Through-the-Patients-Le.aspx. Accessed September 14, 2012.

150. Faden RR, Becker C, Lewis C, Freeman J, Faden AI. Disclosure of information to patients in medical care. Med Care. 1981;19(7): 718-733.

151. Stevenson FA. The strategies used by general practitioners when providing information about medicines. Patient Educ Couns. 2001;43(1): 97-104.

152. Nair K, Dolovich L, Cassels A, et al. What patients want to know about their medications. Focus group study of patient and clinician perspectives. Can Fam Physician. 2002;48:104-110.

153. Xu F. Informing patients about drug effects using positive suggestion. J Manag Care Pharm. 2008;14(4):395-396.

154. Tarn DM, Paterniti DA, Williams BR, Cipri CS, Wenger NS. Which providers should communicate which critical information about a new medication? Patient, pharmacist, and physician perspectives. J Am Geriatr Soc. 2009;57(3):462-469.
155. Myers ED, Calvert EJ. The effect of forewarning on the occurrence of side-effects and discontinuance of medication in patients on amitriptyline. Br J Psychiatry. 1973;122(569):461-464.

156. Myers ED, Calvert EJ. The effect of forewarning on the occurrence of side-effects and discontinuance of medication in patients on dothiepin. J Int Med Res. 1976;4(4):237-240.

157. Myers ED, Calvert EJ. Information, compliance and side-effects: a study of patients on antidepressant medication. Br J Clin Pharmacol. 1984;17(1):21-25.

158. Gibbs S, Waters WE, George CF. Prescription information leaflets: a national survey. J R Soc Med. 1990;83(5):292-297.

159. Howland JS, Baker MG, Poe T. Does patient education cause side effects? A controlled trial. J Fam Pract. 1990;31(1):62-64.

160. Quaid KA, Faden RR, Vining EP, Freeman JM. Informed consent for a prescription drug: impact of disclosed information on patient understanding and medical outcomes. Patient Educ Couns. 1990;15(3):249-259.

161. Lamb GC, Green SS, Heron J. Can physicians warn patients of potential side effects without fear of causing those side effects? Arch Intern Med. 1994;154(23):2753-2756.

162. Baker D, Roberts DE, Newcombe RG, Fox KA. Evaluation of drug information for cardiology patients. Br J Clin Pharmacol. 1991;31(5)525-531.

163. Gandhi TK, Burstin HR, Cook EF, et al. Drug complications in outpatients. J Gen Intern Med. 2000;15(3):149-154.

164. Happell B, Manias E, Roper C. Wanting to be heard: mental health consumers' experiences of information about medication. Int J Ment Health Nurs. 2004;13(4):242-248.

165. Coulter A. Partnerships with patients: the pros and cons of shared clinical decision-making. J Health Serv Res Policy. 1997;2(2):112-121.

166. Thrasher AD, Earp JA, Golin CE, Zimmer CR. Discrimination, distrust, and racial/ethnic disparities in antiretroviral therapy adherence among a national sample of HIV-infected patients. J Acquir Immune Defic Syndr. 2008;49(1):84-93.

167. Kerse N, Buetow S, Mainous AG 3rd, Young G, Coster G, Arroll B. Physician-patient relationship and medication compliance: a primary care investigation. Ann Fam Med. 2004;2(5):455-461.

168. Schneider J, Kaplan SH, Greenfield S, Li W, Wilson IB. Better physician-patient relationships are associated with higher reported adherence to antiretroviral therapy in patients with HIV infection. J Gen Intern Med. 2004;19(11):1096-1103.

169. Piette JD, Heisler M, Krein S, Kerr EA. The role of patient-physician trust in moderating medication nonadherence due to cost pressures. Arch Intern Med. 2005;165(15):1749-1755.

170. McGinnis B, Olson KL, Magid D, et al. Factors related to adherence to statin therapy. Ann Pharmacother. 2007;41(11):1805-1811.

171. Nguyen GC, LaVeist TA, Harris ML, Datta LW, Bayless TM, Brant SR. Patient trust-in-physician and race are predictors of adherence to medical management in inflammatory bowel disease. Inflamm Bowel Dis. 2009;15(8):1233-1239.

172. Ren XS, Kazis LE, Lee A, Zhang H, Miller DR. Identifying patient and physician characteristics that affect compliance with antihypertensive medications. J Clin Pharm Ther. 2002;27(1):47-56.

173. Loh A, Leonhart R, Wills CE, Simon D, Harter M. The impact of patient participation on adherence and clinical outcome in primary care of depression. Patient Educ Couns. 2007;65(1):69-78.

174. Kahn KL, Schneider EC, Malin JL, Adams JL, Epstein AM. Patient centered experiences in breast cancer: predicting long-term adherence to tamoxifen use. Med Care. 2007;45(5):431-439.

175. Arbuthnott A, Sharpe D. The effect of physician-patient collaboration on patient adherence in non-psychiatric medicine. Patient Educ Couns. 2009;77(1):60-67.

176. Zolnierek KB, Dimatteo MR. Physician communication and patient adherence to treatment: a meta-analysis. Med Care. 2009;47(8):826-834.

177. Greenfield S, Kaplan S, Ware JE Jr. Expanding patient involvement in care: Effects on patient outcomes. Ann Intern Med. 1985;102(4): $520-528$. 
178. Greenfield S, Kaplan SH, Ware JE Jr, Yano EM, Frank HJ. Patients' participation in medical care: effects on blood sugar control and quality of life in diabetes. $J$ Gen Intern Med. 1988;3(5):448-457.

179. O'Connor AM, Rostom A, Fiset V, et al. Decision aids for patients facing health treatment or screening decisions: systematic review. BMJ. 1999;319(7212):731-734.

180. Butow P, Devine R, Boyer M, Pendlebury S, Jackson M, Tattersall MH. Cancer consultation preparation package: changing patients but not physicians is not enough. J Clin Oncol. 2004;22(21):4401-4409.

181. Griffin SJ, Kinmonth AL, Veltman MW, Gillard S, Grant J, Stewart M. Effect on health-related outcomes of interventions to alter the interaction between patients and practitioners: a systematic review of trials. Ann Fam Med. 2004;2(6):595-608.

182. Williams GC, McGregor H, Zeldman A, Freedman ZR, Deci EL, Elder D. Promoting glycemic control through diabetes self-management: evaluating a patient activation intervention. Patient Educ Couns. 2005;56(1):28-34.

183. Loh A, Simon D, Wills CE, Kriston L, Niebling W, Härter M. The effects of a shared decision-making intervention in primary care of depression: a cluster-randomized controlled trial. Patient Educ Couns. 2007;67(3):324-332.

184. Mullan RJ, Montori VM, Shah ND, et al. The diabetes mellitus medication choice decision aid: a randomized trial. Arch Intern Med. 2009;169(17):1560-1568.
185. Parchman ML, Zeber JE, Palmer RF. Participatory decision making, patient activation, medication adherence, and intermediate clinical outcomes in type 2 diabetes: a STARNet study. Ann Fam Med. 2010;8(5):410-417.

186. US Census Bureau. Income in the past 12 months 2006 [FactFinder]. Available from: http://factfinder.census.gov/servlet/ STTable?_bm=y\&-geo_id=01000US\&-qr_name=ACS_2006_EST G00_S1901\&-ds_name=ACS_2006_EST_G00_\&-redoLog=false. Accessed July 3, 2008.

187. US Census Bureau. Educational attainment 2006 [FactFinder]. Available from: http://factfinder.census.gov/servlet/STTable?_

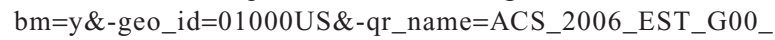
S1501\&-ds_name=ACS_2006_EST_G00. Accessed July 3, 2008.

188. Grieco EM, Cassidy RC. Overview of race and hispanic origin 2000. US Census Bureau; 2001. Available from: http://www.census.gov/ $\operatorname{prod} / 2001 \mathrm{pubs} / \mathrm{c} 2 \mathrm{kbr} 01-1 . p d f$. Accessed July 3, 2008.

189. Clifford S, Barber N, Horne R. Understanding different beliefs held by adherers, unintentional nonadherers, and intentional nonadherers: application of the Necessity-Concerns Framework. J Psychosom Res. 2008;64(1):41-46

190. Eraker SA, Kirscht JP, Becker MH. Understanding and improving patient compliance. Ann Intern Med. 1984;100(2):258-268.
Patient Preference and Adherence

\section{Publish your work in this journal}

Patient Preference and Adherence is an international, peer-reviewed, open access journal focusing on the growing importance of patient preference and adherence throughout the therapeutic continuum. Patient satisfaction, acceptability, quality of life, compliance, persistence and their role in developing new therapeutic modalities and compounds to

\section{Dovepress}

optimize clinical outcomes for existing disease states are major areas of interest. This journal has been accepted for indexing on PubMed Central. The manuscript management system is completely online and includes a very quick and fair peer-review system. Visit http://www.dovepress.com/ testimonials.php to read real quotes from published authors. 